Original Article

doi:10.29052/IJEHSR.v6.i1.2018.23-30

\title{
Prevalence of nicotine dependence among adults in Karachi, Pakistan
}

\section{Adnan Zia Shamsi, Sumbul Tasneem, Iqra Haider, Mah Rukh Aslam \& Humera Sarwar}

Faculty of Pharmacy, Hamdard University

Corresponding Author Email: adnanshamsi205@gmail.com

Received 14/3/2018; Accepted 29/3/2018; Published 31/3/2018

\section{Abstract}

Background: World Health Organization states that smoking is presently the major reason for the death of one in every ten adults worldwide. The most astounding commonness of smoking is found more in gatherings of young adults and falls consistently in more seasoned age populace. Experimentation of smoking is usually seen during adolescence, but sufficient understanding of factors analogous to early initiation remains indescribable. Dependence is a conduct in which a person or an individual has blunt control with destructive repercussion. A number of reasons contribute in continuation of this dependence property, the majority of which include friends and social circle.

Methodology: The focus of the research study is to get into account the ramification, extensiveness and reasons behind smoking in specifically young adults. A cross-sectional study was conducted; data were collected through a self-designed questionnaire. A total of 153 university students were included with a response rate of $100 \%$, having mean age $22 \pm 2.14$ years. Data were analyzed using SPSS ver. 20 and Microsoft Excel 2013.Cross-tabulation was done using Chi-square test and one sample t-test.

Results: The study results indicate that majority of the subjects started smoking between the age group of 17 -20 years, under the influence of their social gatherings, mostly due to friend circle, while the other reasons may include family, stress, and anxiety. $67.2 \%$ smoke cigarette along with their friends while $26.4 \%$ of the respondents were habitual of smoking alone.

Conclusion: There are many factors which influence the rate of nicotine dependence among students, the majority of which includes the absence of medical guidance, lack of will, family and friends habits and withdrawal effects.

\section{Keywords}

Dependence, Nicotine, Smoking, Young adults

\section{Introduction}

The gravity of medical, cognitive and societal harm that can be prompt by the dependence, jointly with the attribute that it breaches the individual's liberty of choice, means that it is appropriate to consider it as an example of psychiatric disorder ${ }^{1}$. The aim is to isolate the subject from the harmful substances at a slow pace to promote re-adjustment to normal functioning of the body ${ }^{2}$. Dependence is a conduct in which a person or an individual has blunt control with destructive repercussion. It evolves when the neurons reshape due to continuing drug submission and functions only in the presence of specified medication or drug. Once the medication or drug is socially inhibited, a number of physiological reactions pass off that can be explained as withdrawal syndrome. Devoted smokers modulate their nicotine intake and blood levels by regulating the frequency and potency of their tobacco use to attain the psychoactive outcomes.

The core constituent of tobacco is nicotine that transforms it to possess addictive or habit-forming character. Raw and unburned tobacco holds the capability of causing oral cancer along with gum diseases due to carcinogenic toxins ${ }^{3}$. As the tobacco is lightened, the smoke is evolved containing carbon monoxide and 4000 different toxic components in 
the form of a fine aerosol having particle size so small that settles down in the alveolar surface without any hindrance ${ }^{4}$. Nicotine slides down to the lungs through smoke particles, where rapid absorption occurs in the pulmonary venous circulation. This absorbed nicotine moves towards the brain by entering the arterial circulation from lungs resulting in the cholinergic receptor binding. This nicotine binding at the interface between subunits of receptors allows the entry of calcium and sodium stimulating the voltage-dependent calcium channel promoting more calcium to enter the cell. This calcium influx helps in the release of neurotransmitters ${ }^{4}$.

One of the leading causes of preventable deaths is smoking ${ }^{5}$. World Health Organization states that smoking is presently responsible for the killing of one in ten adults worldwide (5 million deaths per annum $)^{6}$. In 2010, approximately $17 \%$ of deaths were from smoking. It further increased death rate from 150,000 deaths per year to 480,000 deaths per year up to 2015 and may increase up to 800,000 deaths per year till $2030^{7}$. It has been evaluated that the prevalence of tobacco use is about $36 \%$ in males and $9 \%$ in female. Smoking and disease conditions related to smoking are more common in youth nowadays and falls consistently in more seasoned age populace ${ }^{8}$. Despite being harmful young adults are greatly involved in such activities and sufficient understanding of factors analogous to early initiation remains indescribable ${ }^{9}$. A number of reasons contribute in continuation of this dependency property, the majority of which include friends and social circle ${ }^{10}$.

The objective of this survey-based research study is to evaluate the reasons and consequences behind the prevalence of nicotine dependence within the specific age group and to provide the best possible solutions to overcome the devastating circumstances of nicotine dependence.
Methodology

A cross-sectional study was conducted involving university students. Demographic data were gathered targeting the age and factors associated with nicotine dependence from the students by using a self-designed questionnaire.

Out of 153 study subjects, the majority were the students of various departments of Hamdard University, Karachi. An online Google form was also used for the collection of data. University students from 18-25 years of age, individual who smoked a cigarette at least for 01 years, physically and cognitively healthy individual were all included in the study sample.

A verbal consent was obtained from the individuals participating in the study by letting them know that this data is solely for research purpose and would not be disclosed for any other purpose. The gathered data was evaluated by the $20^{\text {th }}$ version of SPSS and Microsoft Excel 2013. Descriptive statistics were performed. Cross-tabulation was done using Chisquare test and one sample t-test.

\section{Results}

The mean age of participants was calculated to be $22 \pm 2.14$ years in which $149(97 \%)$ were male respondents, while 4(3\%) were female respondents (Table 1). The marital status of the study population was also noted that is $145(94.78 \%)$ subjects were single and $8(5.22 \%)$ subjects were married.

Among the study subjects, 133(86.9 \%) were unemployed students whereas, 20 (13.1\%) were the students who were employed in different organizations on part-time job (Table 1). 
Table 1: Demographics

\begin{tabular}{lll}
\hline Mean Age & $\mathbf{2 2} \pm \mathbf{2 . 1 4}$ & \\
\hline Gender & Male N (\%) & Female N (\%) \\
\hline & $149(97 \%)$ & $4(3 \%)$ \\
\hline Employment status & Unemployed (students) N (\%) & Employed N (\%) \\
\hline Marital Status & $133(86.9 \%)$ & $20(13.1 \%)$ \\
\hline & Single N (\%) & Married N (\%) \\
\hline
\end{tabular}

Table 2: Factors associated with smoking habits

\begin{tabular}{|c|c|c|c|}
\hline Investigation & Responses & Frequency & Percentage \\
\hline \multirow[t]{3}{*}{ Restrictions on Smoking } & Yes & 84 & 52.8 \\
\hline & No & 47 & 29.6 \\
\hline & Sometimes & 22 & 13.8 \\
\hline \multirow{2}{*}{$\begin{array}{l}\text { Difficulty in going to } \\
\text { smoking areas }\end{array}$} & Yes & 91 & 59.5 \\
\hline & No & 62 & 40.5 \\
\hline \multirow[t]{3}{*}{ Smokers in Family/Friends } & Yes & 40 & 26.1 \\
\hline & No & 79 & 51.6 \\
\hline & May Be & 34 & 22.2 \\
\hline \multirow[t]{3}{*}{ Medical guidance } & Yes & 41 & 26.8 \\
\hline & No & 100 & 65.4 \\
\hline & Maybe & 12 & 7.8 \\
\hline \multirow[t]{3}{*}{ Tried to quit smoking } & Yes & 80 & 52.3 \\
\hline & No & 63 & 41.2 \\
\hline & Sometimes & 10 & 6.5 \\
\hline \multirow[t]{4}{*}{ Reason for smoking again } & Stress & 55 & 35.9 \\
\hline & Friends & 77 & 50.3 \\
\hline & Family & 7 & 4.6 \\
\hline & Others & 14 & 9.2 \\
\hline \multirow[t]{2}{*}{ Want to quit } & Yes & 94 & 61.4 \\
\hline & No & 59 & 38.6 \\
\hline \multirow[t]{3}{*}{ Duration to quit } & Within 6 Months & 28 & 18.3 \\
\hline & After 6 Months & 20 & 13.1 \\
\hline & As per willpower & 105 & 68.6 \\
\hline \multirow{3}{*}{ Withdrawal effects } & Yes & 52 & 34 \\
\hline & No & 69 & 45.1 \\
\hline & Sometimes & 32 & 20.9 \\
\hline \multirow[t]{3}{*}{ Smoking (Hazardous/not) } & Yes & 122 & 79.7 \\
\hline & No & 25 & 16.3 \\
\hline & Maybe & 6 & 3.9 \\
\hline \multirow[t]{7}{*}{ Factors of smoking } & Dependence & 34 & 22.2 \\
\hline & Stress & 37 & 24.2 \\
\hline & Fun & 6 & 3.9 \\
\hline & Friends & 50 & 32.7 \\
\hline & Relaxation & 6 & 3.9 \\
\hline & Stress relieving & 5 & 3.3 \\
\hline & None & 14 & 9.2 \\
\hline
\end{tabular}


A significant correlation was observed during the evaluation through paired sample t-test between feelings before and after smoking, restrictions at home and difficulty in going to non-smoking areas and efforts to quit smoking versus reasons for smoking relapse, giving us the $\mathrm{p}$-value of $<0.01$ in all the pairs (Table 2).

Table 3: Paired Samples Test giving significant results $\mathbf{p}<0.01$ for different attributes

\begin{tabular}{|c|c|c|c|c|c|c|c|c|}
\hline & & \multirow[t]{2}{*}{ Mean } & \multirow[t]{2}{*}{$\begin{array}{c}\text { Std. } \\
\text { Deviation }\end{array}$} & \multirow[t]{2}{*}{$\begin{array}{l}\text { Std. } \\
\text { Error } \\
\text { Mean }\end{array}$} & \multicolumn{2}{|c|}{$\begin{array}{l}\text { 95\% Confidence } \\
\text { Interval of the } \\
\text { Difference }\end{array}$} & \multirow[t]{2}{*}{ t-value } & \multirow[t]{2}{*}{ P-value } \\
\hline & & & & & Lower & Upper & & \\
\hline $\begin{array}{l}\text { Pair } \\
1\end{array}$ & $\begin{array}{l}\text { Feeling before } \\
\text { smoking - Feeling } \\
\text { after smoking }\end{array}$ & 0.49 & 1.328 & 0.107 & 0.278 & 0.702 & 4.564 & 0 \\
\hline $\begin{array}{l}\text { Pair } \\
2\end{array}$ & $\begin{array}{l}\text { Restrictions if any - } \\
\text { Difficulty in going } \\
\text { at non-smoking } \\
\text { areas }\end{array}$ & 0.242 & 0.787 & 0.064 & 0.116 & 0.367 & 3.803 & 0 \\
\hline $\begin{array}{l}\text { Pair } \\
3\end{array}$ & $\begin{array}{l}\text { Tried to quit } \\
\text { smoking - Reason } \\
\text { of smoking again }\end{array}$ & -0.216 & 1.026 & 0.083 & -0.38 & -0.052 & -2.601 & 0.01 \\
\hline
\end{tabular}

Table 4 shows that a total of 80 subjects tried to quit smoking but 32 of them again started to smoke due to stress while 41 subjects continued smoking because of friends and gatherings.

Table 4: Association between efforts to quit smoking and reasons of smoking again.

\begin{tabular}{llccccccc}
\hline & & \multicolumn{3}{c}{ The reason for smoking again } & \multicolumn{2}{c}{ P value } \\
\cline { 2 - 9 } & & Stress & Friends & Family & Others & Total & \\
\hline Tried to & No & 22 & 32 & 1 & 8 & 63 & \\
Quit & Smoking & 32 & 41 & 4 & 3 & 80 & \\
\cline { 2 - 9 } & Yes & Sometimes & 1 & 4 & 2 & 3 & 10 & $\mathrm{p}<0.05$ \\
\hline Total & & 55 & 77 & 7 & 14 & 153 & \\
\hline
\end{tabular}

The highest number of population $19.5 \%$ started smoking between the age of $17 \& 18$ (Figure 1). 55\% participants were addicted due to friends whereas 35\% respondents were smoking due to stress (Figure 2) among which $67 \%$ people smoke daily (Figure 3). 67.3\% respondents were smoking with friends and $26.4 \%$ people smokes alone (Figure 4). In this study, we found that $24.5 \%$ people consume nicotine through cigar and $8.2 \%$ people use the pipe as an alternative source of cigarette (Figure 5). 67.9\% smokers smoke less than 10 cigarettes per day whereas $22 \%$ people smoke up to 20 cigarettes per day (Figure 6). 27.45\%, 21.56\% \& $27.45 \%$ respondents claimed to feel craving, anxiety \& stress respectively whereas the most of the participants $(n=85) 55.55 \%$ feels relaxed after smoking (Figure 7). Major factors for smoking initiation were found to be friend circle, family background and stress in which some of the participants were facing physiological issues that do not let them quit smoking. 
Figure 1: Percentile age of smoking initiation

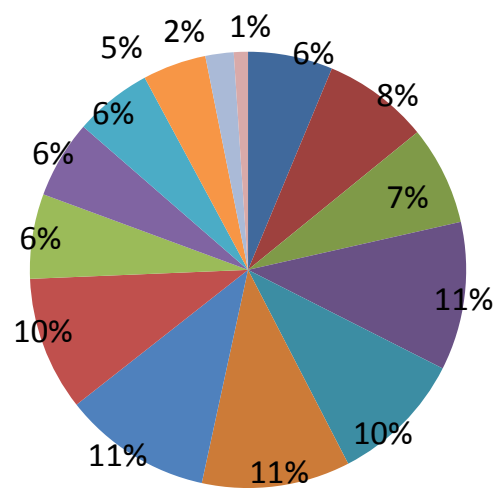
12 yrs
13 yrs
14 yrs
15 yrs
16 yrs
17 yrs
18 yrs
19 yrs

Figure 2: Reasons for smoking

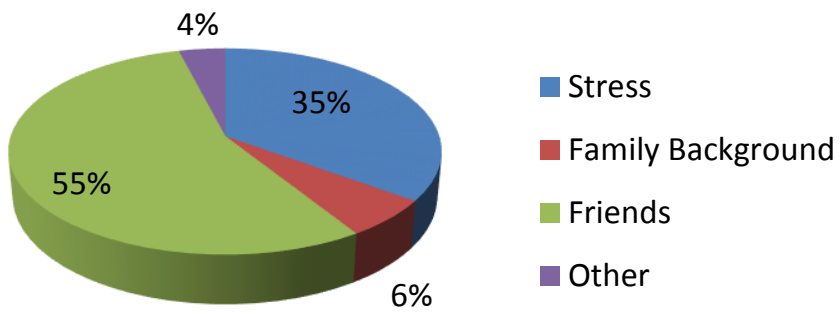

Figure 3: Smoking habits of respondents

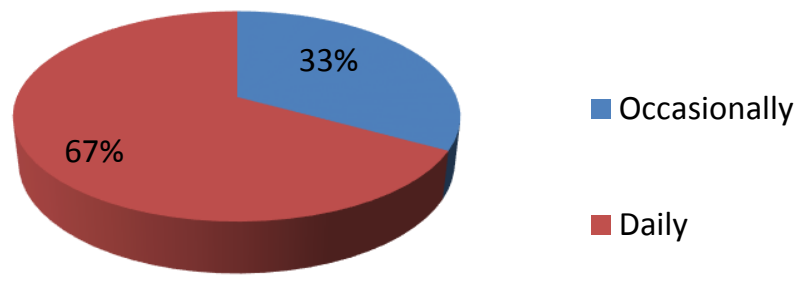

Figure 4: Smoking habit according to the environment

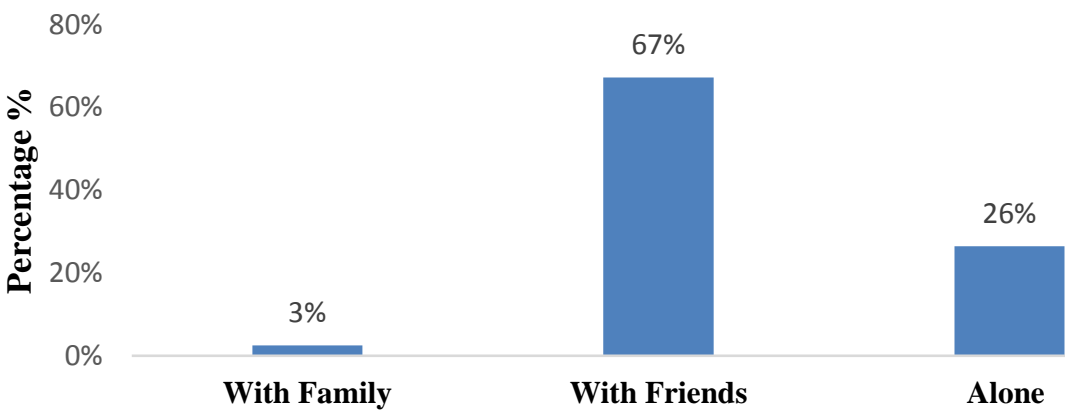


Figure 5: Source of nicotine another cigarette

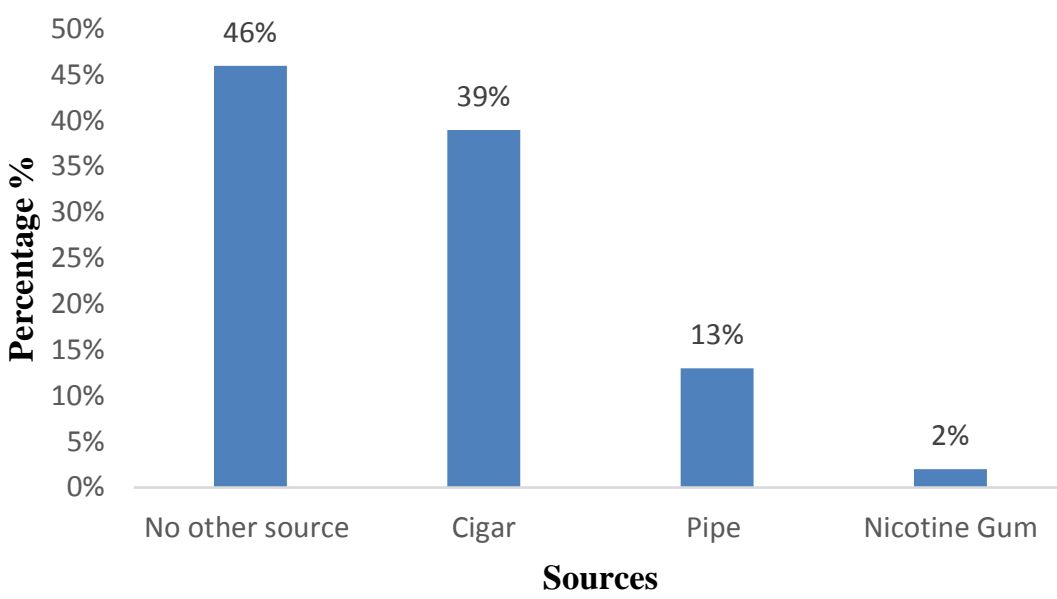

Figure 6: Number of cigarettes smoked per day

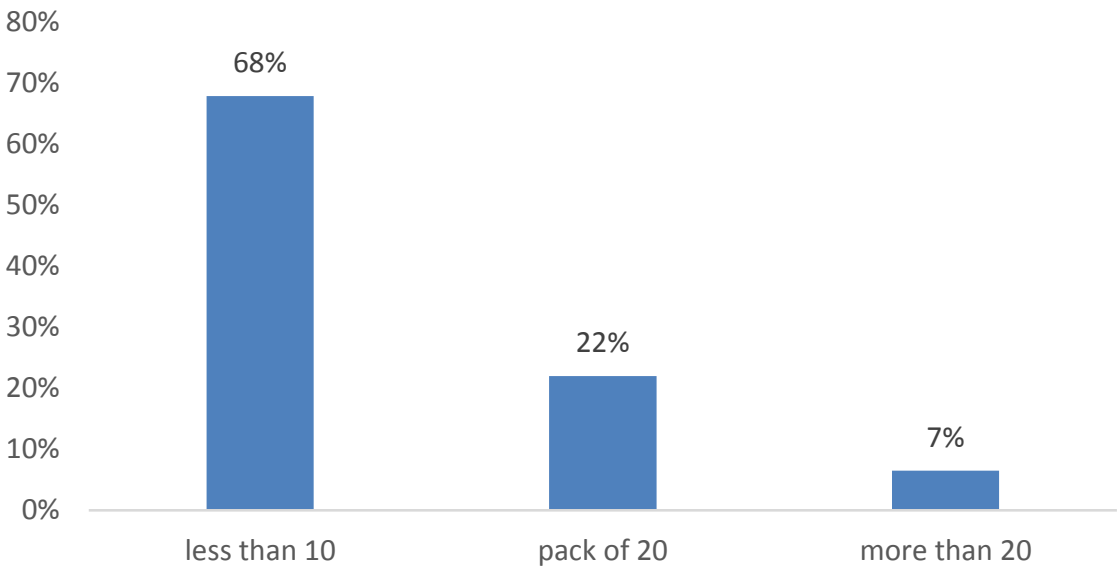

Figure 7: Feeling of respondents before and after smoking

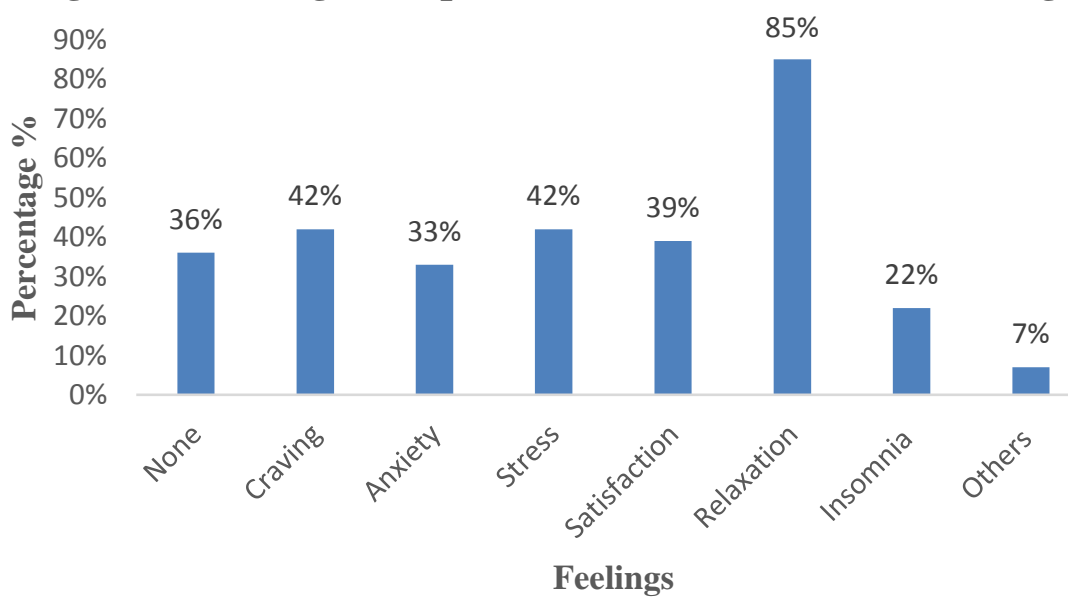




\section{Discussion}

There are a number of a research article that claims nicotine as one of the topmost lethal factors around the globe but unfortunately, none of them suggest the best possible way to overcome the devastating outcomes of nicotine dependence ${ }^{2}$. As compared to other published article, this study reveals that majority of the study subjects initiated cigarette smoking during early age and prolong exposure increased disease susceptibility among youth (figure 1). The highest percentage of smoking is found in males (table 1) and they were mostly students associated with different fields of educations including healthcare sciences, engineering sciences, and others.

About $65 \%$ of the subjects claimed to lack parental as well as professional guidance that could be a beneficial source of reducing smoking tendency (table 2). An environment that may educate people regarding the hazardous effect of passive smoking, prevention of smoking at home and public places specifically in the presence of children must be promoted. The study revealed that around 52.3\% individuals tried to quit smoking (table 2) upon which majority reported some withdrawal effects including anxiety and craving (figure 7) whereas they felt relaxed once they initiated smoking again. As discussed earlier medical guidance can be a source of education to downstream such physiological effects of an individual ${ }^{10}$. $79.7 \%$ $(n=122)$ individuals accepted that smoking is injurious to health and $68.6 \%$ wanted to restrict their smoking habit but unfortunately due to lack of motivation they failed to do so. Health care system may suggest such people for the utilization of nicotine patches or nicotine gums instead of smoking cigarettes and causing their liver a severe damage $^{11}$ but unfortunately, only $1.3 \%$ of the total included population had access to such products (figure 5) that could ultimately save them from some chronic physiological conditions like liver failure.

Moreover, the study results revealed that subjects who even tried to quit smoking couldn't do so either because of stress, friends, family gatherings or self
- cravings (table 4). According to a report by American Thoracic society individual with initial withdrawal stages may experience constipation, chest tightness, difficulty concentrating, dry throat, sleep difficulty, anxiety, and depression. All such feeling lead to a relapse of smoking among such individual $^{12}$.

\section{Conclusion}

Through this study, it has been concluded that students need guidance regarding smoking and its hazards. This study helps us to state that majority of the smokers starts smoking at a very early age and remains in contact with nicotine for a very long period of time. Healthcare education programs for young generation are much needed to educate young students using every possible media as a platform.

\section{Conflicts of Interests}

None.

\section{Acknowledgment}

All the authors are thankful to Dr. Saman Usmani and Students of Hamdard University for their cooperation.

\section{Funding}

None.

\section{References}

1. West R. Theories of addiction. Addiction. 2001; 96(1):3-13.

2. Erik MacLaren, Understanding Tolerance, Dependence, and Addiction.

3. Frazier L, Yu E, Sanner J, Liu F, Udtha M, Cron S, Coulter S, Bogaev RC. Gender differences in self-reported symptoms of depression among patients with the acute coronary syndrome. Nursing research and practice; 2012.

4. Khuwaja AK, Kadir MM. Smoking among adult males in an urban community of Karachi, Pakistan. 2004

5. Centers for Disease Control and Prevention. CDC Fact Sheet-Health Effects of Cigarette Smoking-Smoking \& Tobacco Use. 
6. Prevalence of tobacco smoking. World Health Organization. 2017. Retrieved from: http://www.who.int/gho/tobacco/use/en/

7. Benowitz NL. Nicotine addiction. New England Journal of Medicine. 2010; 362(24):2295-303.7

8. CDC - 50th Anniversary Surgeon General's Report - Smoking \& Tobacco Use. Smoking and Tobacco Use. 2017. Retrieved from: https://www.cdc.gov/tobacco/data_statistics/sg r/50th-anniversary/index.htm

9. Pappas G, Akhtar T, Gergen PJ, Hadden WC, Khan AQ. Health status of the Pakistani population: a health profile and comparison with the United States. American journal of public health. 2001; 91(1):93.
10. Simons-Morton B, Crump AD, Haynie DL, Saylor KE, Eitel P, Yu K. Psychosocial, School, and Parent Factors Associated with Recent Smoking among Early-Adolescent Boys and Girls. Preventive Medicine. 1999; 28(2):138-48.

11. Nicotine addiction, 2005. Retrieved from: www.health.am/mobile/psy/nicotine_addiction _introduction/

12. Tobacco Control Committee of the American Thoracic Society, Patricia Folan, Christine Fardellone, Andrea Spatarella. Withdrawal and Relapse from Tobacco Use, American Thoracic Society. 2013 